\title{
First-Rank Symptoms or Rank-and-File Symptoms?
}

\author{
P. CRICHTON
}

NOV 201996

Kurt Schneider's first-rank symptoms (FRS) of schizophrenia have had an immense influence on the way schizophrenia has been diagnosed in clinical practice throughout the world, especially in Germany, the UK and other Western European countries. They remain an essential component of psychiatric training and are handed on from generation to generation as the gold standard of schizophrenia diagnosis. Trainees are expected to be able to list all the FRS and apply them in clinical examinations. FRS are often of particular importance in forensic psychiatric assessments where a psychiatrist usually visits a prison inmate only once and has to rely more on the mental state examination than on observations of behaviour gathered over time.

FRS have also greatly influenced schizophrenia research and became important constituents of the Present State Examination (Wing et al, 1974) and the Research Diagnostic Criteria (Spitzer et al, 1978).

The RDC formed the basis of the DSM-III criteria for schizophrenia (American Psychiatric Association, 1980) which were subsequently adopted in research protocols throughout the world. One of the consequences of this has been that research concentrated on so-called positive symptoms of schizophrenia, such as FRS, and until more recently neglected the negative symptoms which may significantly handicap the patient. Even in ICD-10 (World Health Organization, 1992), for example, FRS appear prominently in the first three groups of symptoms "that have special importance for the diagnosis", negative symptoms are relegated to the end of the list, in the last two of nine groups.

\section{Schneider's views on the significance of FRS}

What claims did Schneider make of FRS? In Klinische Psychopathologie (1980) he states that, in the absence of an organic psychosis, the presence of a first-rank symptom indicates a diagnosis of schizophrenia. Although FRS are sufficient, they are not necessary for the diagnosis, which can still be made if second-rank symptoms or even only expressional or behavioural symptoms ("Ausdrucksymptome”) are present. FRS should not, in Schneider's view, be regarded as having explanatory power or theoretical significance with regard to the aetiology of schizophrenia; they are simply useful diagnostic tools. FRS do not, he believed, have a common foundation, although he points out that some of them, such as thought withdrawal and thought broadcasting seem to relate to the "so-called loss of ego boundaries".

\section{Findings of subsequent investigators}

Unfortunately Schneider was mistaken in his belief that FRS could invariably distinguish schizophrenia from cyclothymia (Mellor, 1982). FRS have subsequently been found in several conditions, including neurotic and "character disorders" (Carpenter et al, 1973), but most commonly in mania where studies have shown that between 6 and $23 \%$ of manic or manic-depressive patients assessed had FRS (Taylor \& Abrams, 1973; Wing \& Nixon, 1975; Brockington et al, 1978). Kraepelin (1920), by the way, believed towards the end of his life that there could be an overlap between schizophrenia and cyclothymia. Finally, the heritability of FRS is zero (McGuffin et al, 1984).

\section{FRS and the temporal lobes}

Trimble (1990) made a brave new attempt to restore some of the pristine brilliance of the now jaded colours of FRS by suggesting that FRS are not pathognomonic of schizophrenia, but signify temporal lobe pathology.

However, the results of the main MRI studies which have investigated temporal lobe size in schizophrenic patients and of neuropathological studies of the temporal lobes of schizophrenic patients remain inconclusive.

Liddle et al (1992) using PET found some evidence of an association between the reality distortion syndrome (delusions and hallucinations in general, not FRS in particular) and altered regional cerebral blood flow (rCBF) in the medial temporal lobe. McGuire et al (1993) in a SPET study noticed that auditory hallucinations (hearing 
voices in general, not Schneiderian third-person auditory hallucinations in particular) were associated with increased activity in Broca's area, i.e. in the left inferior frontal region.

In summary, the suggested link between FRS and temporal lobe abnormalities remains somewhat tenuous. Indeed, the possibility that abnormalities in other regions of the brain may also be involved in the development and manifestation of FRS cannot be excluded.

\section{FRS - a chance cluster?}

Part of the attraction of FRS is their "free-floating" quality: they do not presuppose or imply any aetiological theories, which often have the regrettable characteristic of being disproven and discarded, nor do they have prognostic implications (Carpenter et al, 1973; Kendell et al, 1979). This “advantage" has a price: if FRS have no association with antecedents or consequences, it is difficult to see what their significance as a symptom cluster could be (Boyle, 1990). Schneider seems to be partly aware of this problem when he breezily admits that his use of the term "symptom" in FRS is somewhat idiosyncratic. He is not, he says, using "symptom" in the normal medical sense of evidence of a disease, but to refer to a "more or less characteristic, invariably detectable feature of a purely psychopathological 'state-coursecomplex' (Zustand-Verlauf-Gebilde)" (Schneider, 1980). In other words, FRS are not in fact symptoms at all in the usual sense of that word.

\section{Methodological problems in Schneider's work}

Another serious and fundamental problem about FRS is this: what reasons are there for Schneider, and for us, to believe that some symptoms of schizophrenia are more important for the diagnosis than others and that the particular symptoms which Schneider lists are especially important? Information about methodology is virtually nonexistent in Klinische Psychopathologie (1980) and we can really only guess how he determined which symptoms should be promoted to the first rank. We know, however, from this monograph that he accepted Kraepelin's system of classification and distinguished between "abnormal personalities", "abnormal reactions", "organic psychoses", "schizophrenia" and "cyclothymia". One possibility is that, given his view of schizophrenia, he could have taken a group of psychotic patients, excluded those with a clearly organic psychosis, those with a reactive psychosis and those with obvious cyclothymia, performed a statistical analysis of the symptoms of the remaining psychotic patients (presumed to have schizophrenia) and dubbed the most frequently found symptoms in this group "first-rank symptoms". I strongly suspect, however, that if he had used a method similar to this, or indeed any method at all, he would have said so and supplied us with the numbers of patients in his diagnostic groups and some statistics about symptom frequencies. Although some contemporaries of Schneider used statistics extensively in their psychiatric research, it must also, in fairness, be admitted that the statistical approach was fairly alien to many of the more clinically and psychopathologically orientated psychiatrists of Schneider's generation. Statistical methods were also much less sophisticated than they are today.

Schneider does, however, give us a few statistics when he discusses a study intended to demonstrate, not how he arrived at his choice of FRS, but how the use of FRS leads to a clear-cut diagnosis in most cases. Between 1932 and 1936 he reviewed nearly 3000 patients admitted to the psychiatric department of the municipal hospital in Schwabing in Munich. He found 1647 cases of abnormal personality and abnormal reaction, 941 cases of schizophrenia and only 28 cases where the diagnosis was unclear. When he compared these 1647 cases of abnormal personality and abnormal reaction with 166 cases of cyclothymia, there were only another seven cases which remained unclear. He admits, however, that the "diagnostic scope" with respect to schizophrenia is "very broad and vague", compared with cyclothymia (Schneider, 1980). This study points to another problem which has bedevilled schizophrenia research for nearly a century: is the Schwabing cohort comparable to Kraepelin's cohort and to the many other cohorts which have subsequently been studied? In addition, it seems likely that both cohorts contained unrecognised cases of organic psychosis, some of which would now be more readily detected with modern investigative techniques.

For these reasons it seems difficult to resist the conclusion that FRS were derived solely from Schneider's clinical experience. Indeed, throughout Klinische Psychopathologie he appeals to his clinical experience to support his views and not to data from studies (with the exception of the Schwabing study quoted above). Problems of sampling, observer bias and reliability are not mentioned. It seems unlikely that such a methodically flawed study would not even be considered for publication in a peer-review journal. Schneider, by the way, is not alone in this. Similar criticisms 
can be levelled against Kraepelin (Shepherd, 1995). It would, however, be unfair to expect psychiatrists of an earlier era to conform to modern notions of scientific exactitude, which, in turn, may appear ludicrously simple-minded and homespun in 50 years' time. If this is so, the question then arises: why do psychiatrists all over the world still believe in the importance of FRS?

\section{The attractions of FRS}

One of the reasons may be the apparent simplicity of FRS. Schneider seems to be offering us an immensely seductive short-cut to the diagnosis of a subtle and complex disorder: if FRS are present and an organic psychosis has been included, the diagnosis is schizophrenia. Indeed, at first glance, the FRS themselves seem straightforward enough. In the Present State Examination, however, Wing et al (1974) found it necessary to expand on and clarify some of the FRS to improve inter-rater reliability. But Koehler (1979), a student of Schneider, has shown that the problem goes much further than this. He examined the way in which a number of prominent researchers (Fish, Mellor, Taylor and Heisser, Wing) have interpreted some of Schneider's FRS and found considerable discrepancies. Passivity experiences, hallucinations and delusional phenomena, according to Koehler, occupy a continuum and can be interpreted narrowly or widely according to individual preference. With thought broadcasting, for example, should thoughts which leave the subject's head be counted as FRS or do they also have to be shared by others? O'Grady (1990) found in acute psychiatric in-patients that FRS were not specific to schizophrenia, but were more likely to be associated with schizophrenia if they were defined narrowly.

Given the failure of several theoretically motivated attempts to explain schizophrenia (for example the failure of explanations in terms of "double-bind", "the schizophrenogenic mother", etc.) Schneider's pragmatic and apparently theoryfree approach must have seemed irresistibly refreshing. It has to be remembered that although the first German edition of "Clinical Psychopathology" appeared in 1946, the first English translation did not appear until 1959, i.e. at a time when psychological and psychosocial theories completely dominated contemporary thinking and research on schizophrenia. But Schneider's approach was far from being theoryfree. It has already been noted that he had adopted Kraepelin's classificatory system for the psychoses. In addition, he openly acknowledged that he had espoused the phenomenological approach of Jaspers. This requires a long and detailed interview, in difficult cases perhaps several interviews, in which the examiner tries to encourage the patient to describe his or her subjective experiences. The examiner then attempts to recreate these experiences in his or her own mind, to "understand" (= verstehen) them and, with the help of observations of the patient's behaviour, to identify patterns of psychopathological phenomena (Jaspers, 1912 (1968)). Clearly the idea that this method is a shortcut to the diagnosis of schizophrenia is mistaken. One wonders whether the very large cohort of nearly 3000 patients in Schneider's Schwabing study were all subjected to this extremely rigorous procedure or whether only their case-notes were scrutinised. Schneider does not tell us.

Perhaps Kurt Schneider's personal prestige also contributed to the success of his FRS. Although in 1931 he became Director of the German Research Institute for Psychiatry in Munich founded by Kraepelin in 1918, and held an honorary professorship at the University of Munich from 1934, he managed to distance himself from politics and from the pro-Nazi pronouncements and activities of many of his colleagues, who included his namesake, Carl Schneider. During the 1930 s and early 1940 s he rejected the offer of several professorships in protest against the Nazis (Huber, 1994). He seems to have inspired not only affection, but a sense of religious veneration in his pupils. Kisker (1968) mentions that some of them referred to his Klinische Psychopathologie as the "New Testament". As Schneider's highly respected medical publishers (Georg Thieme Verlag) quote this remark on the cover of the 12th German edition of Klinische Psychopathologie (Schneider, 1980), it was presumably not thought to have been made tongue-incheek, but in full seriousness.

\section{Conclusions}

Thus Schneider almost certainly based his FRS entirely on his own clinical impressions which were invested with his personal authority. No scientific evidence was found in Schneider's writings to establish the special importance of FRS for the diagnosis of schizophrenia. He presented no data to suggest that FRS are anything more than a chance cluster and indeed conceded that they are not even symptoms in the normal sense of the word "symptom". Subsequent investigators have cast doubt on the validity of FRS. It is time, therefore, to strip first-rank "symptoms" of their colours 
which have dazzled us too long and demote them to the rank and file.

\section{Acknowledgements}

The author wishes to thank Dr Hans-Peter Kapfhammer and Dr C. Cordess for their very helpful comments on an earlier draft of this paper, and Dr A. M. Reveley and Dr S. Greer for their advice.

\section{References}

American Psychiatric Association (1980) Diagnostic and Statistical Manual of Mental Disorders (3rd edn) (DSM-III) Washington, DC: APA.

BoYle, M. (1990) Schizophrenia - A Scientific Delusion? London and New York: Routledge.

Brockington, I. F., Kendell, R. E. \& LefF, J. P. (1978) Definitions of schizophrenia: concordance and prediction of outcome. Psychological Medicine, 8, 387-398.

Carpenter, W. T., Strauss, J. J. \& Muleh, S. (1973) Are there pathognomonic symptoms of schizophrenia? Archives of General Psychiatry, 28, 847-852.

HUBER, G. (1994) Images in psychiatry: Kurt Schneider, 1887-1967. American Journal of Psychiatry, 151, 1492.

JASPERS, K. (1912) Die phänomenologische Forschungsrichtung in der Psychopathologie. Zeitschrift für die gesamte Neurologie und Psychiatrie, 9, 391-408. (Translation: The phenomenological approach in psychopathology. British Journal of Psychiatry (1968), 114, 1313-1323.)

Kendell, R. E., Brockington, I. F. \& LeFF, J. P. (1979) Prognostic implications of six alternative definitions of schizophrenia. Archives of General Psychiatry, 36, 25-31

KiSKER, K. P. (1968) Kurt Schneider. Der Nervenarzt, 39, 97-98.

KOEHLER, K. (1979) First-rank symptoms of schizophrenia: questions concerning clinical boundaries. British Journal of Psychiatry, 134, 236-248.

Kraepeln, K. (1920) Die Erscheinungsformen des Irreseins. Zeitschrift für die gesamte Neurologie und Psychiatrie, 62, 1-29.
(Translated by MARsHaLL, H. (1974) In Themes and Variations in European Psychiatry (eds S. R. Hirsch \& M. Shepherd). Bristol: John Wright and Sons Ltd.)

LidDle, P. F., Friston, K. J., FrITH, C. D., et al (1992) Patterns of cerebral blood flow in schizophrenia. British Journal of Psychiatry, 160, 179-186.

MCGuffin, P., FARmer, A. E., GotTesman, I. I., et al (1984) Twin concordance for operationally defined schizophrenia. Archives of General Psychiatry, 41, 541-545.

McGuire, P. K., Shah, G. M. S., Murray, R. M. (1993) Increased blood flow in Broca's area during auditory hallucinations in schizophrenia. Lancet, 342, 703-706.

Mellor, C. S. (1982) The present status of first-rank symptoms. British Journal of Psychiatry, 140, 423-424.

O'GrADY, J. C. (1990) The prevalence and diagnostic significance of Schneiderian first-rank symptoms in a random sample of acute psychiatric in-patients. British Journal of Psychiatry, 156, 496-500.

SCHNEIDER, K. (1980) Klinische Psychopathologie, 12th edition. Stuttgart: Georg Thieme Verlag. (5th edition translated by M. W. Hamilton (1959) Clinical Psychopathology. New York: Grune and Stratton.)

SHEPHERD, M. (1995) The two faces of Emil Kraepelin. British Journal of Psychiatry, 167, 174-183.

SPITZER, R., ENDICOTT, J. \& RoBINs, E. (1978) Research diagnostic criteria. Archives of General Psychiatry, 35, 773-782.

TAYLOR, M. A. \& ABRAMs, R. (1973) The phenomenology of mania. A new look at some old patients. Archives of General Psychiatry, 29, 520-522.

Trnmble, M. R. (1990) First-rank symptoms of Schneider, a new perspective? British Journal of Psychiatry, 156, 195-200.

WING, J. K., COOPER, J. E. \& SARTORTUS, N. (1974) Measurement and Classification of Psychiatric Symptoms. Cambridge: Cambridge University Press.

- \& NrxoN, J. (1975) Discriminating symptoms in schizophrenia. Archives of General Psychiatry, 32, 853-859.

World Health Organization (1992) The Tenth Revision of the International Classification of Diseases and Related Health Problems (ICD-10). Geneva: WHO.

Paul Crichton, MRCPsych, Maudsley Hospital, Denmark Hill, London SE5 8AZ

(First received 3 October 1995, final revision 19 March 1996, accepted 1 April 1996) 